Article

\title{
Spray Drying of a Subcritical Extract Using Marrubium vulgare as a Method of Choice for Obtaining High Quality Powder
}

\author{
Aleksandra Gavarić ${ }^{1}$, Jelena Vladić ${ }^{1}{ }^{\oplus}$, Rita Ambrus ${ }^{2}$, Stela Jokić ${ }^{3, *}{ }^{\circledR}$, \\ Piroska Szabó-Révész ${ }^{2}{ }^{10}$, Milan Tomić ${ }^{4}$, Marijana Blažić ${ }^{5}$ and Senka Vidović ${ }^{1, *}$ \\ 1 Faculty of Technology, University of Novi Sad, Bulevar cara Lazara 1, 21000 Novi Sad, Serbia; \\ cvejina@uns.ac.rs (A.G.); vladicjelena@gmail.com (J.V.) \\ 2 Institute of Pharmaceutical Technology and Regulatory Affairs, University of Szeged, Eotvos 6, 6720 Szeged, \\ Hungary; arita@pharm.u-szeged.hu (R.A.); revesz@pharm.u-szeged.hu (P.S.-R.) \\ 3 Faculty of Food Technology Osijek, Josip Juraj Strossmayer University of Osijek, Franje Kuhača 20, \\ 31000 Osijek, Croatia \\ 4 Faculty of Agriculture, University of Novi Sad, Trg Dositeja Obradovica 8, 21000 Novi Sad, Serbia; \\ milanto@polj.uns.ac.rs \\ 5 Department of Food Technology, Karlovac University of Applied Sciences, Josip Juraj Strossmayer Square 9, \\ 47000 Karlovac, Croatia; marijana.blazic@vuka.hr \\ * Correspondence: stela.jokic@ptfos.hr (S.J.); senka.vidovic@uns.ac.rs (S.V.); \\ Tel.: +385-31-224-333 (S.J.); +381-21-485-3731 (S.V.)
}

Received: 9 August 2019; Accepted: 8 October 2019; Published: 11 October 2019

\begin{abstract}
White horehound (Marrubium vulgare L.), is a grey-leaved perennial herb, belonging to Lamiaceae family, distributed in Eurasia and northern Africa. Despite the fact that $M$. vulgare has been used since ancient times in treating diverse diseases, it is only in the last decade or so that scientists have been able to lay the foundation for its potential pharmacological actions from the results observed through the prism of ethnopharmacological use of this species. The novelty of this study was that subcritical water extraction, acknowledged as a powerful extraction technology to recover phenolic compounds, was coupled with spray drying. The subcritical horehound extract, obtained using optimal process parameters, was used as a liquid feed in spray drying. Maltodextrin was used as a carrier in a concentration of $10 \%$. Thus, two M. vulgare powders, carrier-free and $10 \%$ $\mathrm{MD}$, were produced. Comprehensive powders characterization was conducted in order to evaluate their quality. Results confirmed that spray drying can be used as a method of choice for obtaining high quality horehound powders which kept the amorphous structure constant after 6 months.
\end{abstract}

Keywords: Marrubium vulgare; subcritical water extraction; spray drying; powder characterization

\section{Introduction}

The aerial parts and root of Marrubium vulgare L. have been traditionally used in the Mediterranean areas of Europe and North Africa. More familiar as a white horehound, it belongs to the genus Marrubium, formed by nearly 30 species [1]. This genus is an abundant source of secondary metabolites, including nine different types of diterpenes and their derivatives, more than ten flavonoid constituents, phenylpropanoids and theirglycosides [2]. The most studied secondary metabolite, marrubiin, a labdane diterpenoid, was isolated for the first time from $M$. vulgare leaves [3]. The reason why this chemotaxonomic marker was the subject of many studies is due to the fact it possesses several biological activities such as antioxidant, anti-inflammatory and vasorelaxant effects [4]. This perennial plant, with morphological characteristics reminiscent of a mint [5], shows numerous diverse pharmacological 
effects. It was reported that a hydroalcoholic extract of the aerial parts and root of horehound exerts significant antispasmodic activity, which means that it can be used as an expectorant for acute/chronic bronchitis, colds and in cases of asthma [6]. According to another study, the hydroalcoholic extract also shows analgesic effects when administered per os or intraperitoneally [7]. A series of in vivo experiments were performed in rats seeking antidiabetic effects in horehound. The results were positive, since there was a more than $60 \%$ decrease of the blood glucose level when aqueous extracts were administered [8]. The methanol extract of horehound herba revealed moderate activity when evaluated against five Gram positive bacteria: Bacilus subtilis, Sthapylococcus epidermidis and S. aureus, Pseudomonas vulgaris and Escherichi coli [9]. Furthermore, this plant demonstrated a strong effect against methicillin-resistant Staphylococcus aureus. [10]. Beside its medicinal use, extracts of horehound herba are also used as flavouring agents, especially by the brewing industry as a substitute for hops [5], in candies [11], and as an ingredient of cough pastilles [12].

According to a market research report, horehound was reported as the top-selling herbal dietary supplement ingredient in mainstream US retail outlets for the fifth consecutive year. In this channel, horehound supplement sales in 2017 increased for 12.3\% from 2016 [13]. Records of the medicinal use of horehound confirm that this herb is still commonly used for its expectorant and cough-suppressant properties, especially in the form of cough drops and lozenges. According to European Medicines Agency guidelines, horehound is usually used in combination with 3 to 5 herbal substances in Europe. In agreement with guidelines from the US FDA, dietary supplements appear in a number of forms inclusive of tablets, powders, capsules, softgels, gelcaps and liquids. Powders have many benefits over liquid extracts including higher stability, reduced bulk size, higher concentration of bioactives, simple manipulation and shipment, and finally easier standardization [14]. Therefore, spray drying imposes as technique of choice for obtaining a solid phase herbal powders from liquid feed in a single step.

The main purpose of this study was to estimate the efficiency of spray drying technology to microencapsulate phenolic compounds from horehound subcritical extract obtained at optimal conditions of process parameters. This extract, used as liquid feed, was obtained through subcritical water extraction which has been acknowledged as a powerful extraction technology to recover phenolic compounds from different matrices $[15,16]$. The obtained powders were further investigated with reference to their physical and chemical properties. To the best of our knowledge, the subcritical horehound extract has not been applied yet as a liquid feed for spray drying process.

\section{Materials and Methods}

\subsection{Plant Material}

M. vulgare harvested in 2015 was bought from Chamomilla (Banatski Karlovac, Serbia) a local supplier of cultivated plants. The aerial parts of $M$. vulgare were air-dried in a thin layer, collected in the paper bags, and stored at room temperature. Afterwards, the dried M. vulgare herba was grounded in a domestic blender and the particle size of grounded material was determined using vibration sieve sets (CISA, Cedaceria, Spain). The mean particle size of M. vulgare herba used in investigation was $0.28 \mathrm{~mm}$.

\subsection{Chemicals}

Reagents used in the various methods, 1,1-diphenyl-2-picrylhydrazyl hydrate (DPPH), Folin-Ciocalteu reagent and ( \pm )-catechin were purchased from Sigma (Sigma-Aldrich Chemie GmbH, Sternheim, Germany). The following reagents were also purchased from Sigma-Aldrich Chemie: iron (III)-chloride, potassium hexacyanoferrate (III), sodium hydrogen phosphate anhydrous, sodium dihydrogen phosphate andtrichloroacetic acid. Gallic acid was purchased from Sigma (St. Louis, MO, USA). Maltodextrin of dextrose equivalent (DE) 16.5-19.5 (Sigma-Aldrich Chemie GmbH) was used as a carrier material. All other chemicals and reagents were of analytical grade. 


\subsection{Liquid Extract and Liquid Feed Preparations}

Subcritical water extraction (SWE) at optimal process conditions (temperature of $200^{\circ} \mathrm{C}$, extraction time of $20.29 \mathrm{~min}$ and absence of $\mathrm{HCl}$ ) defined in our previous study, was used to obtain liquid extract which was further used as a liquid feed. The scheme of subcritical water extraction apparatus used is presented in previously published paper [17]. In certain amount of liquid feed no carrier was added prior to the drying. Maltodextrin (MD) of dextrose equivalent (DE) 16.5-19.5 was used as a carrier material. Procedure of preparation of liquid feed with $10 \%$ MD was descibed in our previous study [14]. Table 1 with composition of prepared formulations, amount of added carrier and drying conditions is provided down below.

Table 1. Composition of prepared formulations prior to spray drying.

\begin{tabular}{cccccc}
\hline Sample & $\begin{array}{c}\text { Total Solids } \\
{[\mathbf{m g} / \mathbf{m L}]}\end{array}$ & $\begin{array}{c}\text { Amount of Added } \\
\text { Maltodextrin }[\mathrm{g}]\end{array}$ & $\begin{array}{c}\text { Volume of Spray Dried } \\
\text { Liquid Feed [L] }\end{array}$ & $\begin{array}{c}\boldsymbol{T}_{\text {inlet }} \\
{\left[{ }^{\circ} \mathbf{C}\right]}\end{array}$ & $\begin{array}{c}\boldsymbol{T}_{\text {outlet }} \\
{\left[{ }^{\circ} \mathbf{C}\right]}\end{array}$ \\
\hline MVP 0\% MD & 40.90 & 0 & 2 & $130 \pm 5$ & $75-80$ \\
MVP 10\% MD & 44.99 & 8.18 & 2 & $130 \pm 5$ & $75-80$ \\
\hline
\end{tabular}

\subsection{Spray Drying Process and its Efficiency}

The pilot scale spray dryer (APV Anhydro AS, Søborg, Denmark) used for spray drying of prepared liquid feed is presented in Figure 1. A laboratory peristaltic pump was used to transfer the liquid feed into the drying chamber. For each run, $2 \mathrm{~L}$ of liquid feed was dried. Liquid feeds were dried at inlet temperature, $T_{\mathrm{i}}=130 \pm 5^{\circ} \mathrm{C}$, while outlet temperature, $T_{0}$ was maintained at $75-80^{\circ} \mathrm{C}$. During the production of the dry extract (powder), rotary disk, within atomizer, delivered speed from 20,000 to 21,000 rpm. The obtained powder was separated from heating medium in a cyclone and collected in glass bottles, sealed and kept protected from air and humidity. The particle production efficiency (i.e., powder recovery) is determined gravimetrically as ratio of mass of the powder obtained in the collecting vessel after spray drying and mass of total solids measured in the liquid feed. Process efficiency is expressed as the weight percentage.

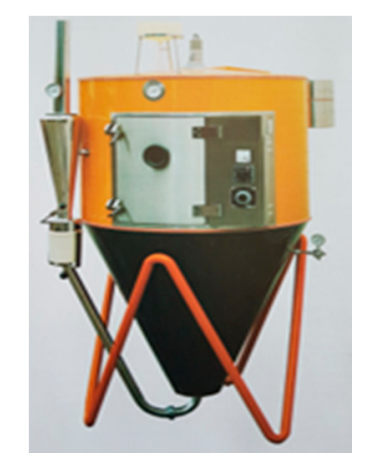

Figure 1. Pilot scale spray dryer.

\subsection{Analysis of MVPs Stability Properties}

\subsubsection{Moisture Content}

Moisture contents of MVPs were determined according to standard procedure described in the official Pharmacopeia (Ph. Jug. IV). The gravimetric method, based on water removal by heating, was carried out in an oven at $105^{\circ} \mathrm{C}$ until achieving constant mass. Measurement of the moisture content was performed promptly after the spray drying. All experiments were performed in three replicates. 


\subsubsection{Hygroscopicity}

All powder samples (approx. $1 \mathrm{~g}$ ) were placed in desiccator supplied with $\mathrm{NaCl}$ saturated solution $(70 \% \mathrm{RH})$ at $25^{\circ} \mathrm{C}$. The hygroscopicity was measured after $48 \mathrm{~h}$. Hygroscopicity was expressed as a gram of absorbed water per $100 \mathrm{~g}$ of dry extract powder. All experiments were performed in three replicates [14].

\subsection{Analysis of Mops Solubility and Wettability Properties}

Water Solubility (WSI) and Water Absorption (WAI) Indexes

The WSI and WAI were determined according to a previously described method [18]. Certain amounts of powder $(1.25 \mathrm{~g})$ and water $(15 \mathrm{~mL})$ were vigorously mixed in a $50 \mathrm{~mL}$ centrifuge tube. Afterwards, the mixture was incubated in a water bath at $30{ }^{\circ} \mathrm{C}$ for $30 \mathrm{~min}$, and centrifuged for $15 \mathrm{~min}$ at $3000 \mathrm{rpm}$. The supernatant was decanted in a pre-weighed Petri dish, while particles were concentrated as a solid pellet at the bottom of the centrifuge tube. Both supernatant and pellet were placed in an oven and dried at $105^{\circ} \mathrm{C}$ overnight. The amount of solids in the dried supernatant was calculated as a percentage of the total dry solids in the $1.25 \mathrm{~g}$ of sample, and represents WSI. WSI, reconstitution property, is used as an indicator of degradation of powder constituents. WAI was calculated as the mass of solid pellets remaining after centrifugation divided by the mass of the original dry sample. WAI is a measure of the products ability to absorb water. WAI depends on the availability of hydrophilic groups and on the gel-forming capacity of macromolecules. The hydrophilic groups are responsible for binding of water molecules. The low WAI indicates better stability during the storage. All experiments were performed in three replicates.

\subsection{Analysis of Mvps Flow Behavior Properties}

\subsubsection{Bulk Density}

Bulk density was determined by measuring the volume of a known mass of powder sample in a graduated glass cylinder. M. vulgare powder $(1 \mathrm{~g})$ was placed in a $25 \mathrm{~mL}$ graduated cylinder. Afterwards, the bulk density was calculated from the difference between the mass of empty glass cylinder and the mass of glass cylinder with powder sample. Bulk density was expressed as mg of powder per $\mathrm{mL}$.

\subsubsection{Powder Characterization}

Powder flowability, a key property in filling and by calculating the Hausner ratio and the Carr Index (CI). The Hausner ratio is calculated from the ratio between the bulk and tapped densities of the powder. The Carr Index is another measure of flowability, also calculated from the two densities of the powder [19].

\subsubsection{Particle Size Analysis}

In order to measure the particle size distribution of the prepared powders, LEICA Image Processing and Analysis System (LEICA Q500MC, LEICA Cambridge Ltd., Cambridge, UK) was used. The size was determined using 350 particles per product. The particles were described in detail by their length, breadth, surface area, perimeter and roundness. The Malvern apparatus (Malvern Mastersizer Scirocco 2000; Malvern Instruments Ltd., Worcestershire, UK) was used for laser diffraction required for determination of powders particle size distributions. The sample (approx. $1 \mathrm{~g}$ ) was loaded into the feeder tray. The dispersion air pressure was fixed at 2.0 bar to determine if particle attrition has occurred. Obscuration was kept between $10.0 \%$ and $15.0 \%$ throughout the whole measurement duration. The particle size distribution was characterized by the $\mathrm{D}(0.1), \mathrm{D}(0.5)$ and $\mathrm{D}(0.9)$ values and the specific surface area (SSA). 


\subsubsection{Morphology-Scanning Electron Microscopy (SEM)}

The morphology of the MVPs particles was examined by SEM (Hitachi S4700, Hitachi Scientific Ltd., Tokyo, Japan). In order to induce electric conductivity on the surface of the samples, a sputter coating apparatus (Bio-Rad SC 502, VG Microtech, Uckfield, UK) was applied. The air pressure was 1.3-13.0 mPa.

\subsection{Analysis of Mvps Crystallographic and Thermal Properties}

\subsubsection{Differential Scanning Calorimetry Analysis (DSC)}

The Mettler Toledo DSC 821e thermal analysis system with the STARe thermal analysis program V6.0 (Mettler Inc., Schwerzenbach, Switzerland) was used for DSC measurements. The sample (approx. 2-5 mg) was examined in the temperature range between $25^{\circ} \mathrm{C}$ and $300{ }^{\circ} \mathrm{C}$. The heating rate was $10^{\circ} \mathrm{C} \mathrm{min}^{-1}$. During the DSC investigation, argon was used as inert carrier gas, at a flow rate of $10 \mathrm{~L} / \mathrm{h}$.

\subsubsection{X-ray Powder Diffraction Analysis (XRDP)}

The physical state of samples was evaluated by X-ray powder diffraction (XRPD). The BRUKER D8 advance X-ray powder diffractometer (Bruker AXS GmbH, Karlsruhe, Germany) with $\mathrm{Cu} K \lambda \mathrm{I}$ radiation $(\lambda=1.5406 \AA$ ) and a VÅNTEC-1 detector (Bruker AXS GmbH) were used for analyses of diffraction patterns. Scanning of samples were performed at $40 \mathrm{kV}$ and $40 \mathrm{~mA}$. The angular range was $3^{\circ}-40^{\circ} 2 \theta$, at increment time of $0.1 \mathrm{~s}$ and increment size of $0.007^{\circ}$. All operations, including $\mathrm{K} \alpha 2$ stripping, background removal and smoothing of the area under the diffractograms peaks, were performed using the DIFFRACplus EVA software. The structural characterization by DSC and XRPD analyses were repeated after 6 months using the samples stored at room temperature in exicator.

\subsection{Analysis of Mvps Bioactive Compounds}

\subsubsection{Total Phenol Content}

The contents of total phenolic compounds (TP) in horehound herbal powders were determined by the Folin-Ciocalteu procedure [20]. Gallic acid was used as standard compound for preparation of calibration curve, and absorbance of the samples was measured at $750 \mathrm{~nm}(6300$ Spectrophotometer, Jenway, Dunmow, UK). Content of phenolic compounds in dry extracts was expressed as mg GAE per $\mathrm{g}$ of dry extract (mg GAE/g DE). All experiments were performed in three replicates, and results are expressed as mean values.

\subsubsection{Total Flavonoids Content}

The total flavonoids content (TF) was determined in MVPs using aluminum chloride colorimetric assay [21]. Catechin was used as a standard for creation of calibration curve, and absorbance was measured at $510 \mathrm{~nm}$. Content of flavonoids in dry extracts was expressed as mg CE per g of dry extract (mg CE/g DE). All experiments were performed in triplicate, and results were expressed as mean values.

\subsubsection{DPPH Assay}

The free radical scavenging activity of extracts produced from horehound herbal powder was determined using a simple and fast spectrophotometric method [22]. Briefly, the subcritical extracts were mixed with $90 \mu \mathrm{M}$ 2,2-diphenyl-1-picryl-hydrazyl (DPPH) and methanol (95\%) to provide different final concentrations of extract. After $1 \mathrm{~h}$ at room temperature, the absorbance was measured at $517 \mathrm{~nm}$, in triplicates by a 6300 Spectrophotometer (Jenway). Radical scavenging capacity (RSC $(\%)$ ) was calculated according to Equation (1) and expressed as $\mathrm{IC}_{50}$ value, which represents the concentration of extract solution required for obtaining $50 \%$ of radical scavenging capacity: 


$$
\% \text { RSC }=100-\left(A_{\text {sample }} \times 100\right) / A_{\text {blank }}
$$

where $A_{\text {sample }}$ is the absorbance of sample solution and $A_{\text {blank }}$ is the absorbance of control.

\subsubsection{FRAP Assay}

The reducing power of horehound herbal powder was determined by a previously described method [23]. Various concentrations of subcritical extracts were mixed with sodium phosphate buffer ( $2.5 \mathrm{~mL}, 0.2 \mathrm{M}, \mathrm{pH} 6.6)$ and $2.5 \mathrm{~mL}$ of $1 \%$ potassium ferricyanide $\left(\mathrm{K}_{3} \mathrm{Fe}(\mathrm{CN})_{6}\right)$. The mixture was incubated at $50{ }^{\circ} \mathrm{C}$ for $20 \mathrm{~min}$. After incubation, $10 \%$ trichloroacetic acid aqueous solution $(2.5 \mathrm{~mL})$ was added to the mixture, and the mixture was centrifuged for $10 \mathrm{~min}$ at $3000 \mathrm{rpm}$. The obtained supernatant $(2.5 \mathrm{~mL})$ was mixed with bidestillated water $(2.5 \mathrm{~mL})$ and $0.1 \% \mathrm{FeCl}_{3}$ solution $(0.5 \mathrm{~mL})$. Absorbance was measured at $700 \mathrm{~nm}$. Antioxidant activity was expressed as EC50 value $(\mathrm{mg} / \mathrm{mL})$, which causes reduction of $50 \% \mathrm{Fe}^{3+}$ ions in reaction mixture. All experiments were performed in triplicate.

\subsubsection{HPLC Analysis}

Phenolic compounds inMVPs samples (MVP 0\% MD and MVP 10\% MD) were analysed using an Agilent 1200 Series HPLC equipped with a DAD detector (Agilent Technologies, Palo Alto, CA, USA) equipped with Lichrospher ${ }^{\circledR} 100 \mathrm{RP} 18 \mathrm{e}$ column $(5 \mu \mathrm{m}, 250 \times 4 \mathrm{~mm})$. Mobile phase A was formic acid in water $(0.17 \%)$, while mobile phase B was acetonitrile. The injection volume was $10 \mu \mathrm{L}$, and flow rate $0.8 \mathrm{~mL} / \mathrm{min}$ with gradient program (0-53 min 0-100\% B). Stop time of the analysis was $55 \mathrm{~min}$. Compounds were determined by comparing the retention times and absorption spectra (200-400 nm) of unknown peaks with the reference standards (ferulic acid, $p$-coumaric acid, caffeic acid, rutin, hyperoside, 5-hydroxy-2-methylfurfural). The powders were reconstituted in methanol (1:10), macerated for $24 \mathrm{~h}$ and filtered prior to analysis. The investigated samples were analyzed in triplicate.

\section{Results}

\subsection{Process Efficiency}

The optimal spray drying conditions must be satisfied in order to obtain an adequate process efficiency. The dominant factors in spray drying that need to be optimized and monitored throughout the process are feed temperature and air inlet/outlet temperatures [24]. There are several processing obstacles which indirectly affects the properties and yield of the final product. One of them is certainly wall deposition. The wall deposition is created when particles deposit on the surfaces of the inner walls of drying chamber This phenomenon deteriorates the yield of the powder and therefore increase the costs of manufacturing and maintenance [25]. Particles deposit on the wall by attaching to it due to their stickiness which occur above the glass transition temperature, $T_{g}[26,27]$. Apart from monitoring the air inlet temperature, so that on the surface of the product it does not reach more than $10-20{ }^{\circ} \mathrm{C}$ above $T_{\mathrm{g}}$, feed flow rate needs to be constant. When the feed flow rate increases, larger droplets are created and the evaporation rate is lower [28]. When atomizer is supplied with more feed, the particles retain shorter in drying chamber hence the drying time is reduced, contributing in wetter particles. Under these conditions, the particles are more cohesive which cause increase of deposition rate and decrease of yield [25].

Water and ethanol are the most acceptable "green" co-solvents for food-grade products [29]. Despite being safe for human consumption, ethanol has the drawback of being highly flammable, which may limit its wider use in industry. On the contrary, water has the benefits of being nonflammable, flavorless and less restricted in terms of residual solvent. Consequently, the use of water as a common entrainer in a high-pressure extraction process is very attractive and convenient [30]. In our study we used subcritical water extract as liquid feed. The main idea behind introducing subcritical water extraction was to improve extraction yields of desired bioactives and overcome common drawbacks 
of standard solid-liquid extraction. SWE stands out as a promising technique regarding facilitated analyte diffusion, favoured mass-transfer kinetics, decreased viscosity and surface tension of water when temperature is increased. Temperature is the priority factor that affects efficiency and selectivity of SWE [31]. The water in a subcritical state is used as extraction solvent in SWE. Water is regarded as subcritical at temperatures between $100{ }^{\circ} \mathrm{C}$ and $374{ }^{\circ} \mathrm{C}$ and at a pressure high enough to keep it in a liquid state [32]. The drying in pilot scale spray-dryers is considered efficient when recovery in the cyclone is higher than 50\% [33]. The efficiency of two investigated spray drying processes can be considered high since in both cases it was above 50\% (0\% MD: $\eta=58.36 \% ; 10 \%$ MD: $\eta=77.07 \%)$. Furthermore, process efficiency was increased by maltodextrin supplementation which can be related to the influence of MD concentration on the formation of surface core prior to the formation of crust enclosing the drying droplets [34]. Finally, regarding all criteria, in the first place absence of stickiness, absence of wall deposition phenomenon and recovery greater than $50 \%$, process conditions of MVPs production can be considered as suitable.

\subsection{Evaluation of Micrometric Properties and Structure of the Mvps}

According to the literature, the diameter of spray-dried particles depends on the several factors including atomization method used, concentration and viscosity of the encapsulated material and finally drying conditions [35]. Some authors have also emphasized that the particle size is significantly affected by the type of carrier, with the largest sizes resulting from using starch or gum arabic as carriers. There are studies that correlated larger particles with an increased encapsulation efficiency [36]. In Table 2 average length, width, perimeter, area and roundness are presented.

Table 2. Particle size analyses of MVPs obtained by optical microscope.

\begin{tabular}{ccccccc}
\hline Sample & $\begin{array}{c}\text { Average } \\
\text { Value }\end{array}$ & $\begin{array}{c}\text { Length } \\
{[\mu \mathrm{m}]}\end{array}$ & $\begin{array}{c}\text { Width } \\
{[\mu \mathrm{m}]}\end{array}$ & $\begin{array}{c}\text { Perimeter } \\
{[\mu \mathrm{m}]}\end{array}$ & $\begin{array}{c}\text { Area } \\
{\left[\mu \mathbf{m}^{2}\right]}\end{array}$ & Roundness \\
\hline \multirow{2}{*}{ MVP 0\% MD } & Average & 4.43 & 3.57 & 15.49 & 14.40 & 1.33 \\
& SD \pm & 0.12 & 0.38 & 0.99 & 1.17 & 0.07 \\
\hline \multirow{2}{*}{ MVP 10\% MD } & Average & 6.94 & 4.37 & 21.60 & 23.70 & 1.55 \\
& SD \pm & 2.65 & 1.60 & 6.99 & 12.92 & 0.44 \\
\hline
\end{tabular}

In our study, the existence of maltodextrin caused an increase in the average particle size. In sample MVP 0\% MD, particles are smaller (Table 2) than in powder with carrier but aggregation occurred due to presence of cohesiveness. In sample MVP 10\% MD, particles are bigger and more scattered which results in lower level of cohesiveness and their appearance as separated, more individual particles (Figure 2).

Figure 2 presents the morphology of the MVPs particles, changed after the SD process, using SEM with $500 \times(\mathrm{A} 1, \mathrm{~B} 1)$ and $1000 \times(\mathrm{A} 2, \mathrm{~B} 2)$ magnifications. As stated in another study [14], before the SD process the raw MD particles were large sized crystals with irregular needle shape. After the SD process, small individual spherical particles with a smooth surface emerged. In our study, particles in both MVPs are nearly spherical with smooth surface. At 1000x magnification, small holes on the particles surface could be detected due to evaporation of solvent. To visually compare A1, A2 with B1, $\mathrm{B} 2$ in the SEM pictures, it could be seen that without MD (A1, A2) aggregated postures of particles were produced, however using $10 \% \mathrm{MD}(\mathrm{B} 1, \mathrm{~B} 2)$ the individuality of the particles was determinative. There is a strong adherence of smaller particles to the surface of higher magnitude particles (Figure 2B2) which confirmed the lack of crystalline and the presence of amorphous surfaces.

A decreasing particle size trend when $5 \%$ and $10 \%$ MD were added was reported [14], while in our study opposite was noticed when $10 \% \mathrm{MD}$ was added. Tonon et al. also found that a higher maltodextrin concentration in feed solution could lead to the production of larger particles in spray drying, which may be related to the increased feed viscosity with maltodextrin addition [37]. According to Phisut et al., the mean droplet size alters directly with the feed viscosity at constant atomizer speed. 
The higher the feed viscosity, the larger the droplets created during atomization. Therefore, the larger particles obtained by spray drying [36]. Table 3 lists the particle size distribution of two samples, MVP $0 \%$ MD and MVP 10\% MD.

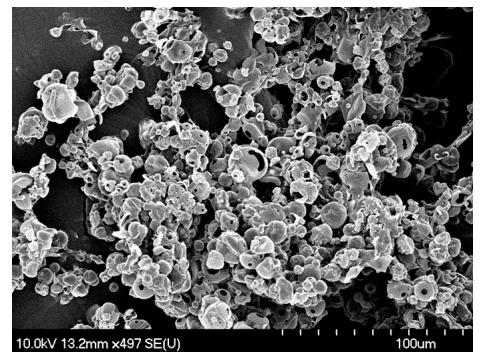

(A1)

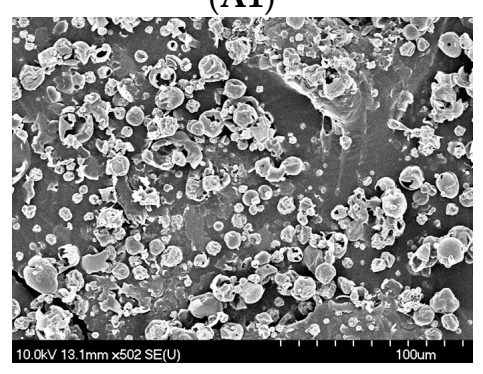

(B1)

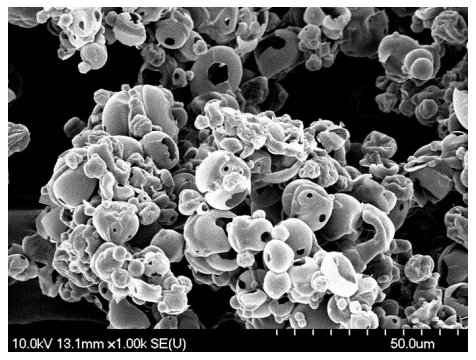

(A2)

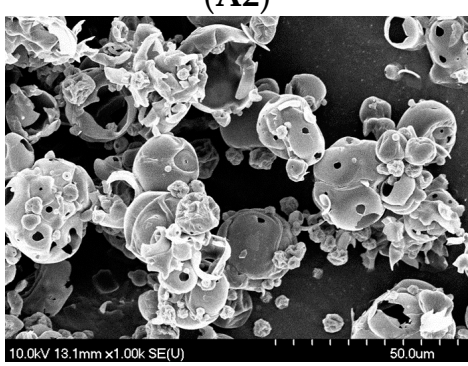

(B2)

Figure 2. Micrographs of the MVPs particles using SEM with 500 $\times$ magnification (A1, B1) and 1000× magnification (A2, B2) where A1, A2 represent MVP 0\% MD and B1, B2 represent MVP 10\% MD.

Table 3. Particle size distribution of MVPs obtained by laser diffraction.

\begin{tabular}{ccccc}
\hline Sample & $\begin{array}{c}\text { D 0.1 } \\
{[\mu \mathrm{m}]}\end{array}$ & $\begin{array}{r}\text { D 0.5 } \\
{[\mu \mathrm{m}]}\end{array}$ & $\begin{array}{c}\text { D 0.9 } \\
{[\mu \mathrm{m}]}\end{array}$ & SSA \\
\hline MVP 0\% MD & 2.700 & 6.920 & 14.840 & 1.150 \\
MVP 10\% MD & 2.791 & 7.252 & 15.882 & 1.100 \\
\hline
\end{tabular}

Spray-drying of the subcritical extract resulted in microsized particles in both samples, with quite similar distribution (Figure 3). Both distribution curves showed log normal shape. Fine decrease in specific surface area, when 10\% MD was added, confirmed that particles are bigger in MVP $10 \%$ MD.

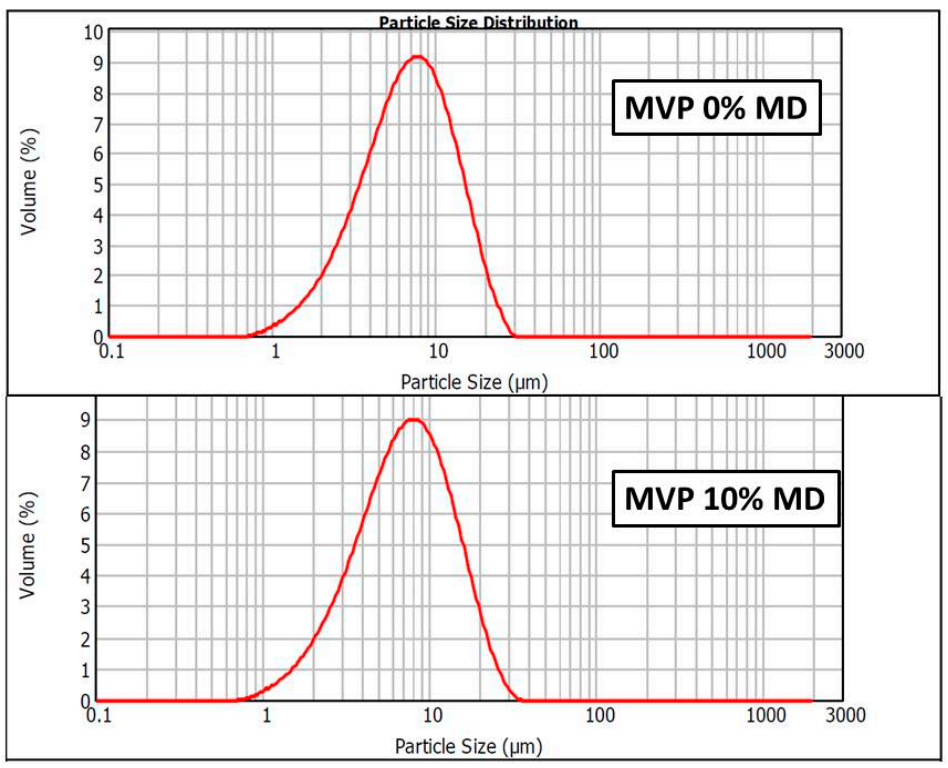

Figure 3. Size distribution of the $0 \%$ MD MVP and 10\% MD MVP. 
In our previous work [14], the XRPD patterns of untreated and spray-dried MD could be seen, confirming its amorphous character. The results of XRPD analysis (Figure 4a) indicate the amorphous state of analysed MVPs without characteristic peak intensities. The presence of MD did not affect the structure of the MVP extract. The amorphous state is convenient since it can provide very fast dissolution of herbal powders, which is important, e.g., for instant products. The XRPD was confirmed by the thermal behaviors of MVPs. According to DSC curves (Figure 4b), the loss of free water was detected below $100{ }^{\circ} \mathrm{C}$ in both cases.

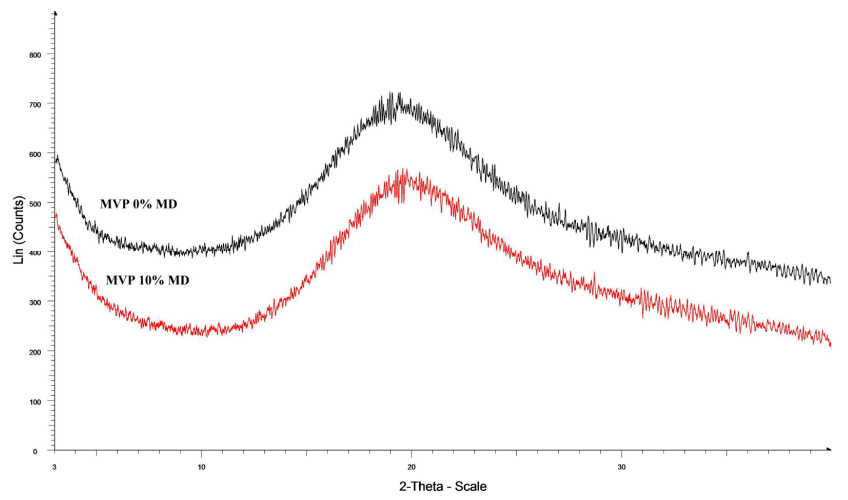

(a)

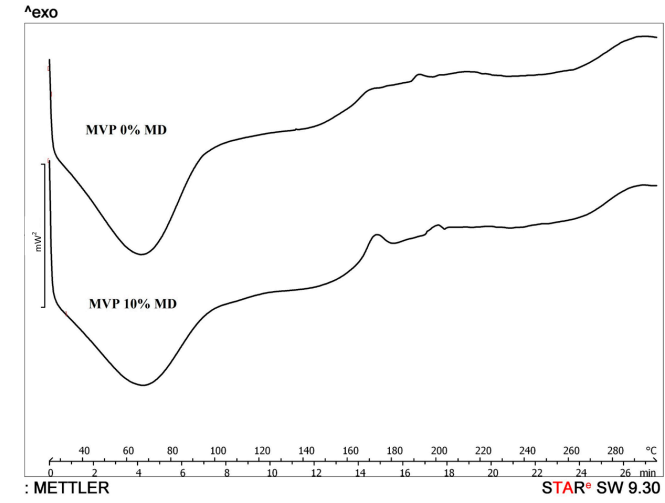

(b)

Figure 4. (a) XRPD patterns of the $0 \%$ MD MVP and 10\% MD MVP; (b) DSC curves of the 0\% MD MVP and $10 \%$ MD MVP.

In the case of MVP 10\% MD sample, this water content should be bigger, because wider signal could be detected. On the DSC curves, no sharp endotherm peaks were detected which indicates an amorphous character (without melting point of crystalline materials) of both samples.

According to the literature (https://ink.springer.com/article/10.1007/s10973-019-08174-z) there could be a $T_{\mathrm{g}}$ of maltodextrin around $132-150{ }^{\circ} \mathrm{C}$ and possibly after its glass transition a small recrystallization could be reached with exothermal event at around $170{ }^{\circ} \mathrm{C}$. During our previous measurements [14], MD decomposed after $300^{\circ} \mathrm{C}$. The solid-phase extract was also amorphous and after its glass transition the recrystallization could be also detected. The structural characterizations were repeated after 6 months (Figure S1) and the character of the amorphous structure was unchanged, which confirmed its stability. The count numbers did not change, which reflected the unaltered amorphous form (500-700 Lin counts).

\subsection{Moisture Content and Hygroscopicity}

The stability, particle size, morphology and rheological behaviour of powders are the main properties affected by moisture content [38]. The lowest moisture content that can be accomplished is favored in terms of adequate storage and manipulation. The most important shift occurs at the glass transition temperature $\left(T_{\mathrm{g}}\right)$, which involves a second-order transition from a rubber-like liquid to a glassy solid state [39]. The main consequences of glass transition are the exponential decrease of molecular mobility and free volume, and an increase in viscosity at temperatures below $T_{\mathrm{g}}$, resulting in structural transformations that are time dependent [40]. Since water has a very low $T_{\mathrm{g}}\left(-135^{\circ} \mathrm{C}\right)$, it is the major component responsible for the significant $T_{\mathrm{g}}$ depression observed in food materials. Accordingly, water is considered to be a strong plasticizer in food systems [41] and that is why, if present in high amounts in produced dry powders, water could jeopardize powders quality by decrease of free flowing properties and increase of caking property.

Moisture contents in MVP 0\% MD were 4.41\% and 3.29\% in MVP 10\% MD. According to the Ph. Eur. classification method regarding weight gain due to moisture sorption, obtained MVPs can be considered as moderately hygroscopic $(2-15 \% w / w)$. The slight decrease in moisture content, 
with maltodextrin supplemented, was expected. The moisture contents of two obtained horehound powders were similar and lower than $5 \%$, as in the case of $S$. montana powders. This low moisture content can provide sufficient shelf life of the dry extracts due to rare occurrence of microbiological contaminations [42]. Results in the same order of magnitude (3-5\%) were previously observed [43] when moisture content of instant tea powder was evaluated. The moisture content of A. millefollium powders (6.10-7.68\%) showed to be higher than in horehound powders [14]. Our literature review supports the hypothesis that there is an effect of moisture content on the physico-mechanical properties of powders. In pharmaceutical industry, microcrystalline cellulose is a common tableting excipient. The moisture content of microcrystalline cellulose is about 3 to $4 \%$, which is in accordance with the United States Pharmacopeia monograph specifications which restrict the moisture content to no more than 5\%. According to these data it is clear that MVPs are adequate not only for application in various food and dietary supplements, but also in the pharmaceutical industry.

Hygroscopicity is also a key property which represents the ability of powder to absorb the moisture from a high relative humidity environment [44]. Hygroscopicities of MVPs were similar, with no significant difference. After $48 \mathrm{~h}$, the hygroscopicity of the investigated carrier-free powder was $21.12 \%$ and $19.83 \%$ for $10 \%$ MD powder. A slight decrease in hygroscopicity was noticed with $10 \%$ MD supplementation, which is expected and consistent with moisture content, since MD increases the $T_{\mathrm{g}}$ of liquid feed. They also observed that the lowest level of hygroscopicity was achieved when the highest maltodextrin concentrations were used [45]. Investigated powder properties are summarized in Table 4.

Table 4. Characterization of MVPs obtained from subcritical liquid feed.

\begin{tabular}{ccc}
\hline Powder Properties & MVP 0\% MD & MVP 10\% MD \\
\hline Moisture content (\%) & 4.41 & 3.29 \\
Hygroscopicity after 48 h (\%) & 21.12 & 19.83 \\
WSI (\%) & 93.18 & 91.19 \\
WAI (\%) & 1.80 & 1.97 \\
\hline
\end{tabular}

\subsection{Water Solubility (WSI) and Water Absorbtion (WAI) Indexes}

The wettability is defined as the ability of a powder bulk to be penetrated by a liquid due to capillary forces [46]. The process of dispersing a dry powder into a liquid can be classified into four steps: wetting, submerging, dispersing and dissolving. The physical properties of a powder related with these four steps are usually labeled under the term "instant properties" [47]. The water solubility index (WSI) is an unavoidable parameter in characterization of dry powders since it demonstrates the powders ability to dissolve in water. Opposite to WSI, water absorption index (WAI) shows powder ability to absorb water. High values of WSI and low values of WAI are favourable. In investigated MVPs, WSI were similar and quite high (above 90\%) (Table 4). This outcome is expected since liquid feeds were prepared from subcritical extracts where water was used as extractant. WSI slightly decreased as 10\% MD was added. The concentration of MD affects the size of the powdered particles and eventually decreases the solubility of the horehound powder. The highest reported WSI for S. montana powder with 50\% MD was $90.55 \%$. In our study, WAI had preferred low values $(\mathrm{WAI}=0.0180 \mathrm{~g} / \mathrm{g}$ of dry powder for carrier-free sample and WAI $=0.0197 \mathrm{~g} / \mathrm{g}$ of dry powder for $10 \%$ MD sample) comparable with ones obtained for S. montana powder with 50\% MD [42]. In investigated A. millefolium carrier-free and 10\% MD powders, WSI were above 70\% while WAI were below 20\% [14].

\subsection{MVPs Flow Behavior Properties}

One of the most important parameters that characterize powders is definitely their bulk density. The powders have to meet bulk density targets to provide consistent weight during packaging [48]. The higher bulk density and lower moisture content in powder bulk are desired properties for packaging and storage [49]. The bulk density of Amaranthus powder increased with a higher maltodextrin 
concentration [50]. There is a correlation between bulk density and particle size. Particles with smaller size reduced the void spaces among them and arranged themselves in closer form. Consequently, the lower particle size led to a higher bulk density [51]. The bulk densities in investigated MVPs were $83.33 \mathrm{mg} / \mathrm{mL}$ in carrier-free powder and $86.96 \mathrm{mg} / \mathrm{mL}$ in $10 \% \mathrm{MD}$ powder. The bulk density was slightly increased with carrier supplementation which is in conrast with published results about decreasing of bulk density of pomegranate powders when MD concentration increased [52]. These values are magnitude of order of $S$. montana powder obtained by adding $10 \% \mathrm{MD}(82.4 \mathrm{mg} / \mathrm{mL})$ [42]. The bulk density measured in A. millefollium powder with $10 \%$ MD was twice lower $(41.31 \mathrm{mg} / \mathrm{mL})$ than bulk densities of MVPs [14]. The cohesive powders favor creation of an open structure supported by the interparticle forces. Consequently, the outcome is a relatively low bulk density of powders [53]. In our case, MVP 0\% MD showed good, free flow character while MVP 10\% MD showed improved cohesive forces between the particles, however we can state that its flowability is passable (Table 5 and Table S1).

Table 5. Flowability expressed by the Carr index and Hausner ratio.

\begin{tabular}{cccc}
\hline Sample & Carr Index (\%) & Hausner Ratio & Flow Character \\
\hline MVP 0\% MD & 15.01 & 1.18 & Good/free flow \\
MVP 10\% MD & 23.23 & 1.30 & Passable/cohesive \\
\hline
\end{tabular}

\subsection{Polyphenol Content in MVPs}

Polyphenols comprise one of the most diverse groups of secondary plant metabolites, which possess a wide palette of biological activities, among them antioxidant, anti-inflammatory, antibacterial, and antiviral functions stand out as most relevant [54]. In addition, a large pool of preclinical research and epidemiological data confirm that plant polyphenols can decelerate the progression of some cancers, reduce the risks of cardiovascular disease, neurodegenerative diseases, diabetes and osteoporosis [55-57]. Since remarkable bioactive potential has been attributed to polyphenolic compounds, it is necessary to determine their content in dry extracts which could be further implemented in various pharmaceutical formulations and dietary supplements.

In comparison with TP values obtained in 10\% MD powders of two herbs, Satureja montana and Achillea millefolium, total phenols in MVPs (TP $=85.20 \mathrm{mg}$ GAE $/ \mathrm{g}$ DE in $0 \% \mathrm{MD}$ sample; $\mathrm{TP}=72.98 \mathrm{mg}$ $\mathrm{GAE} / \mathrm{g} \mathrm{DE}$ in 10\% MD sample) were lower. Consequently, total flavonoids ( $\mathrm{TF}=31.37 \mathrm{mg} \mathrm{CE} / \mathrm{g}$ in $0 \%$ MD sample; $\mathrm{TF}=26.59 \mathrm{mg} \mathrm{CE} / \mathrm{g}$ in $10 \% \mathrm{MD}$ sample) were also lower in relation to $\mathrm{TF}$ in S. montana powder with $10 \% \mathrm{MD}(\mathrm{TF}=118.69 \mathrm{mg} \mathrm{CE} / \mathrm{g})[14,42]$. Total flavonoids in rosemary powder, obtained by spray drying of ethanolic extract, were comparable with TF values of MVPs [58]. The contents of total phenols and flavonoids decreased with the maltodextrin supplement due to dilution of bioactive compounds encapsulated in powder with inert carrier. Other authors investigated the recovery of encapsulated polyphenols from two Salvia officinalis powders (carrier-free and 20\% MD). The powders were produced by spray drying of subcritical water extracts. They reported slightly higher values for total phenols $(\mathrm{TP}=106.26 \mathrm{mg}$ GAE$/ \mathrm{g}$ for $0 \% \mathrm{MD}$ sample and TP $=91.35 \mathrm{mg} \mathrm{GAE} / \mathrm{g}$ for $20 \% \mathrm{MD}$ sample) and total flavonoids ( $\mathrm{TF}=58.97 \mathrm{mg} \mathrm{CE} / \mathrm{g}$ for $0 \% \mathrm{MD}$ sample and TF $=56.98 \mathrm{mg} \mathrm{CE} / \mathrm{g}$ for $20 \%$ MD sample). However, they also observed that in extracts obtained by SWE using water as extractant, significantly lower selectivity towards polyphenols was demonstrated in relation to aqueous ethanol applied as extractant in other modern extraction techniques [59]. Polyphenol contents and antioxidant activities for two MVPs are presented in Table 6.

In order to identify dominant phenolic compounds in MVPs, HPLC analyses were performed and the results are presented in Table 7 . The major compounds are phenolic acids (ferulic acid, $p$-coumaric acid and caffeic acid) and the flavonoids rutin and hyperoside. It could be observed that in all cases, recoveries of both phenolic acids and flavonoids were distinctly higher when maltodextrin was added as carrier (Table 7). In case of rutin, addition of $10 \% \mathrm{MD}$ resulted in more than 4 -fold increase of rutin content. This suggests that MD addition protects bioactives from thermal degradation. 
Table 6. Content (total phenols (TP) and total flavonoids (TF)) and antioxidant activity of MVPs determined by DPPH and reducing power assays.

\begin{tabular}{cccccc}
\hline Sample & $\begin{array}{c}\text { Total Solids } \\
{[\mathbf{m g} / \mathbf{m L}]}\end{array}$ & $\begin{array}{c}\text { TP } \\
\text { [mg GAE/g] }\end{array}$ & $\begin{array}{c}\text { TF } \\
\text { [mg CE/g] }\end{array}$ & $\begin{array}{c}\text { IC }_{\mathbf{5 0}} \\
{[\mathbf{m g} / \mathbf{m L}]}\end{array}$ & $\begin{array}{c}\text { EC }_{50} \\
{[\mathbf{m g} / \mathbf{m L}]}\end{array}$ \\
\hline MVP 0\% MD & 43.7 & 85.1975 & 31.3668 & 0.0204 & 0.0708 \\
MVP 10\% MD & 52.8 & 72.9810 & 26.5851 & 0.0188 & 0.0756 \\
\hline
\end{tabular}

Table 7. Polyphenol content ( $\mu \mathrm{g} / \mathrm{mL}$ extract) in MVPs obtained using HPLC-DAD.

\begin{tabular}{cccccc}
\hline Sample & Ferulic Acid & $\boldsymbol{p}$-Coumaric Acid & Caffeic Acid & Rutin & Hyperoside \\
\hline 0\% MD MVP & 48.77 & 26.42 & 14.27 & 134.46 & 17.43 \\
$10 \%$ MD MVP & 70.69 & 49.61 & 20.96 & 584.55 & 33.28 \\
\hline
\end{tabular}

\subsection{Antioxidant Activity}

There is a discrepancy in the concentrations of polyphenols that are effective in vitro and the ones that are measured in vivo, which are often of an order of magnitude lower. The potency of nutraceuticals to prevent diseases depends on retaining the bioavailability of their active ingredients [60]. Some authors have investigated the retention of antioxidant activity of the encapsulated polyphenols of spray-dried grape seeds, apple skins and olive leaves extracts. They concluded that there is a notable retention of antioxidant activity after encapsulation accomplished by spray drying [61]. In order to test if microencapsulation by spray drying might be useful to protect polyphenols of horehound, two in vitro assays, DPPH and reducing power, were employed. Antioxidant activities of MVPs, expressed as $\mathrm{IC}_{50}\left(\mathrm{IC}_{50}=20.4 \mu \mathrm{g} / \mathrm{mL} 0 \%\right.$ MD sample; $\mathrm{IC}_{50}=18.8 \mu \mathrm{g} / \mathrm{mL}$ for $10 \% \mathrm{MD}$ sample $)$ were lower than the antioxidant activities of herbal powders of A. millefollium and S. montana obtained in our previous studies [14,42]. However, the obtained antioxidant activities for horehound powders were in line with the $\mathrm{IC}_{50}$ values ranging from 17.6 to $24.4 \mu \mathrm{g} / \mathrm{mL}$ of spray dried rosemary hydroalcoholic extract [58]. The reducing power of the horehound powders, expressed as $\mathrm{EC}_{50}$ values, were $70.8 \mu \mathrm{g} / \mathrm{mL}$ in $0 \% \mathrm{MD}$ sample and $75.6 \mu \mathrm{g} / \mathrm{mL}$ in $10 \%$ MD sample.

\section{Conclusions}

Spray drying is a well-recognized technique for transforming fruit juices into powders but not so common when the liquid feed is a water/hydroalcoholic extract of plant material. The major challenge in spray drying is the creation of a standardized herbal dried extract that has the required content of active compounds. Since herbal extracts contain numerous chemical constituents and are inconsistent in composition, it is particularly difficult to conform them to a standard. However, this study shows that spray drying of a subcritical horehound extract can be used as a method of choice for obtaining high quality powders which kept the amorphous structure constant after 6 months storage time. Furthermore, recoveries of both phenolic acids and flavonoids were distinctly higher when $10 \%$ maltodextrin was added as carrier, which suggests that maltodextrin addition protects bioactives from thermal degradation. This is particularly emphasized in the case of rutin content which was 4-fold higher when carrier was included. Considering the antiasthmatic activity of rutin, this study could initiate developing of a dry powder inhalation formulation based on M. vulgare to treat respiratory disorders.

Supplementary Materials: The following are available online at http://www.mdpi.com/1999-4923/11/10/523/s1, Figure S1: XRPD patterns of the MVP 0\% MD and MVP 10\% MD obtained after 6 months storage time, Table S1: Flow character of powder expressed by Hausner ratio and Carr index.

Author Contributions: A.G., S.V., J.V., S.J. and R.A. designed the experiments. J.V., S.J., A.G., R.A., P.S.-R. and M.T. performed the experiments. A.G., S.V., J.V., S.J. and R.A. analyzed the data. All the authors discussed and planned the paper. J.V., S.J., A.G., R.A., P.S.-R. and M.T. drafted the manuscript. M.B. funding acquisition. 
Funding: Financial support was provided by the Bilateral Collaboration between Hungary and Serbia, grant number: HU-SERB, bilateral cooperation, TÉT_16-1-2016-0167 and as part of the "Atrium of Knowledge" project co-financed by the European Union from the European Regional Development Fund and the Operational Programme Competitiveness and Cohesion 2014-2020.

Conflicts of Interest: The authors declare no conflict of interest.

\section{References}

1. Uritu, C.M.; Mihai, C.T.; Stanciu, G.D.; Dodi, G.; Alexa-Stratulat, T.; Luca, A.; Leon-Constantin, M.-M.; Ştefănescu, R.; Bild, V.; Melnic, S.; et al. Medicinal plants of the family Lamiaceae in pain therapy: A review. Pain Res. Manag. 2018, 2018. [CrossRef] [PubMed]

2. Lodhi, S.; Vadnere, G.P.; Sharma, V.K.; Usman, M.D.R. Marrubium vulgare L.: A review on phytochemical and pharmacological aspects. J. Intercult. Ethnopharmacol. 2017, 6, 429-452. [CrossRef]

3. Popoola, O.; Elbagory, A.; Ameer, F.; Hussein, A. Marrubiin. Molecules 2013, 18, 9049-9060. [CrossRef] [PubMed]

4. Bardai, S.; Morel, N.; Wibo, M.; Fabre, N.; Llabres, G.; Lyoussi, B.; Quetin-Leclercq, J. The vasorelaxant activity of marrubenol and marrubiin from Marrubium vulgare. Planta. Med. 2003, 69, 75-76. [CrossRef] [PubMed]

5. Pukalskas, A.; Venskutonis, P.R.; Salido, S.; de Waard, P.; van Beek, T.A. Isolation, identification and activity of natural antioxidants from horehound (Marrubium vulgare L.) cultivated in Lithuania. Food Chem. 2012, 130, 695-701. [CrossRef]

6. Schlemper, V.; Ribas, A.; Nicolau, M.; Cechinel Filho, V. Antispasmodic effects of hydroalcoholic extract of Marrubium vulgare on isolated tissues. Phytomedicine 1996, 3, 211-216. [CrossRef]

7. De Souza, M.M.; De Jesus, R.A.P.; Cechinel-Filho, V.; Schlemper, V. Analgesic profile of hydroalcoholic extract obtained from Marrubium vulgare. Phytomedicine 1998, 5, 103-107. [CrossRef]

8. Boudjelal, A.; Henchiri, C.; Siracusa, L.; Sari, M.; Ruberto, G. Compositional analysis and in vivo anti-diabetic activity of wild Algerian Marrubium vulgare L. infusion. Fitoterapia 2012, 83, 286-292. [CrossRef]

9. Masoodi, M.H.; Ahmed, B.; Zargar, I.M.; Khan, S.A.; Khan, S.; Singh, P. Antibacterial activity of whole plant extract of Marrubium vulgare. Afr. J. Biotechnol. 2008, 7, 86-87.

10. Quave, C.L.; Pieroni, A.; Bennett, B.C. Dermatological remedies in the traditional pharmacopoeia of Vulture-Alto Bradano, inland southern Italy. J. Ethnobiol. Ethnomed. 2008, 4, 5. [CrossRef]

11. Vincenzi, M.; Maialetti, F.; Dessi, M.R. Monographs on botanical flavouring substances used in foods. Fitoterapia 1995, 66, 203-210.

12. Weel, K.G.; Venskutonis, P.R.; Pukalskas, A.; Gruzdiene, D.; Linssen, J.P. Antioxidant activity of horehound (Marrubium vulgare L) grown in Lithuania. Eur. J. Lipid Sci. Technol. 1999, 101, 395-399. [CrossRef]

13. Smith, T.; Lynch, M.E.; Johnson, J.; Kawa, K.; Bauman, H.; Blumenthal, M. Herbal and dietary supplement sales in the US increase 6/8\%. Available online: http://cms.herbalgram. org/press/2015/HerbalDietarySupplementSalesinUSRisein2014.html?ts=1565174083\&signature= 733188db45b6e9f353c16f5df00ec28a (accessed on 7 August 2019).

14. Vladić, J.; Ambrus, R.; Szabó-Révész, P.; Vasić, A.; Cvejin, A.; Pavlić, B.; Vidović, S. Recycling of filter tea industry by-products: Production of A. millefolium powder using spray drying technique. Ind. Crops Prod. 2016, 80, 197-206. [CrossRef]

15. Naffati, A.; Vladić, J.; Pavlić, B.; Radosavljević, R.; Gavarić, A.; Vidović, S. Recycling of filter tea industry by-products: Application of subcritical water extraction for recovery of bioactive compounds from A. uva-ursi herbal dust. J. Supercrit. Fluids 2017, 121, 1-9. [CrossRef]

16. Ju, Y.H.; Huynh, L.H.; Kasim, N.S.; Guo, T.J.; Wang, J.H.; Fazary, A.E. Analysis of soluble and insoluble fractions of alkali and subcritical water treated sugarcane bagasse. Carbohydr. Polym. 2011, 83, 591-599. [CrossRef]

17. Zeković, Z.; Vidović, S.; Vladić, J.; Radosavljević, R.; Cvejin, A.; Elgndi, M.A.; Pavlić, B. Optimization of subcritical water extraction of antioxidants from Coriandrum sativum seeds by response surface methodology. J. Supercrit. Fluids 2014, 95, 560-566. [CrossRef]

18. Phoungchandang, S.; Sertwasana, A. Spray-drying of ginger juice and physicochemical properties of ginger powders. Science Asia 2010, 36, 40-45. [CrossRef] 
19. Carr, R.L. Evaluating flow properties of solids. Chem. Eng. 1965, 72, 163-168.

20. Kähkönen, M.P.; Hopia, A.I.; Vuorela, H.J.; Rauha, J.P.; Pihlaja, K.; Kujala, T.S.; Heinonen, M. Antioxidant activity of plant extracts containing phenolic compounds. J. Agric. Food Chem. 1999, 47, 3954-3962. [CrossRef]

21. Markham, K.R. Techniques of Flavonoid Identification; Academic Press: London, UK, 1982; Volume 31.

22. Espín, J.C.; Soler-Rivas, C.; Wichers, H.J. Characterization of the total free radical scavenger capacity of vegetable oils and oil fractions using 2, 2-diphenyl-1-picrylhydrazyl radical. J. Agric. Food Chem. 2000, 48, 648-656. [CrossRef]

23. Oyaizu, M. Studies on products of browning reaction. Jpn. J. Nutr. Diet. 1986, 44, 307-315. [CrossRef]

24. Liu, Z.Q.; Zhou, J.H.; Zeng, Y.L.; Ouyang, X.L. The enhancement and encapsulation of Agaricus bisporus flavor. J. Food Eng. 2004, 65, 391-396. [CrossRef]

25. Keshani, S.; Daud, W.R.W.; Nourouzi, M.M.; Namvar, F.; Ghasemi, M. Spray drying: An overview on wall deposition, process and modeling. J. Food Eng. 2015, 146, 152-162. [CrossRef]

26. Roos, Y.H. Glass transition temperature and its relevance in food processing. Annu. Rev. Food Sci. Technol. 2010, 1, 469-496. [CrossRef] [PubMed]

27. Shrestha, A.K.; Ua-Arak, T.; Adhikari, B.P.; Howes, T.; Bhandari, B.R. Glass transition behavior of spray dried orange juice powder measured by differential scanning calorimetry (DSC) and thermal mechanical compression test (TMCT). Int. J. Food Prop. 2007, 10, 661-673. [CrossRef]

28. Ozmen, L.T.A.G.; Langrish, T.A.G. A study of the limitations to spray dryer outlet performance. Drying Technol. 2003, 21, 895-917. [CrossRef]

29. Moyler, D.A. Extraction of Flavours and Fragrances. In Extraction of Natural Products Using Near-Critical Solvents; King, M.B., Bott, T.R., Eds.; Blackie Academic and Professional: Glasgow, UK, 1993.

30. Leeke, G.; Gaspar, F.; Santos, R. Influence of water on the extraction of essential oils from a model herb using supercritical carbon dioxide. Ind. Eng. Chem. Res. 2002, 41, 2033-2039. [CrossRef]

31. Plaza, M.; Turner, C. Pressurized hot water extraction of bioactives. TrAC Trends Anal. Chem. 2015, 71, 39-54. [CrossRef]

32. Ramos, L.; Kristenson, E.M.; Brinkman, U.T. Current use of pressurized liquid extraction and subcritical water extraction in environmental analysis. J. Chromatogr. A 2002, 975, 3-29. [CrossRef]

33. Bhandari, B.R.; Datta, N.; Howes, T. Problems associated with spray drying of sugar-rich foods. Drying Technol. 1997, 15, 671-684. [CrossRef]

34. Young, S.L.; Sarda, X.; Rosenberg, M. Microencapsulating properties of whey proteins. 1. Microencapsulation of anhydrous milk fat. J. Dairy Sci. 1993, 76, 2868-2877. [CrossRef]

35. Jafari, S.M.; Assadpoor, E.; He, Y.; Bhandari, B. Encapsulation efficiency of food flavours and oils during spray drying. Drying Technol. 2008, 26, 816-835. [CrossRef]

36. Phisut, N. Spray drying technique of fruit juice powder: Some factors influencing the properties of product. Int. Food Res. J. 2012, 19, 1297-1306.

37. Tonon, R.V.; Brabet, C.; Hubinger, M.D. Influence of process conditions on the physicochemical properties of açai (Euterpe oleraceae Mart.) powder produced by spray drying. J. Food Eng. 2008, 88, 411-418. [CrossRef]

38. Bhandari, B.R.; Hartel, R.W. Phase transitions during food powder production and powder stability. In Encapsulated and Powdered Foods; CRC Press: Boca Raton, FL, USA, 2005; pp. 273-304.

39. Levine, H.; Slade, L. A polymer physico-chemical approach to the study of commercial starch hydrolysis products (SHPs). Carbohyd. Polym. 1986, 6, 213-244. [CrossRef]

40. Roos, Y. Characterization of food polymers using state diagrams. J. Food Eng. 1995, 24, 339-360. [CrossRef]

41. Mani, S.; Jaya, S.; Das, H. Sticky issues on spray drying of fruit juices. In Proceedings of the ASAE/CSAE North-Central Intersectional Meeting, Saskatoon, SK, Canada, 27-28 September 2002; pp. 1-18.

42. Vidović, S.S.; Vladić, J.Z.; Vaštag, Ž.G.; Zeković, Z.P.; Popović, L.M. Maltodextrin as a carrier of health benefit compounds in Satureja montana dry powder extract obtained by spray drying technique. Powder Technol. 2014, 258, 209-215. [CrossRef]

43. Sinija, V.R.; Mishra, H.N.; Bal, S. Process technology for production of soluble tea powder. J. Food Eng. 2007, 82, 276-283. [CrossRef]

44. Chang, Y.X.; Yang, J.J.; Pan, R.L.; Chang, Q.; Liao, Y.H. Anti-hygroscopic effect of leucine on spray-dried herbal extract powders. Powder Technol. 2014, 266, 388-395. [CrossRef] 
45. Angel, R.C.M.; Espinosa-Muñoz, L.C.; Aviles-Aviles, C.; González-García, R.; Moscosa-Santillán, M.; Grajales-Lagunes, A.; Abud-Archila, M. Spray-drying of passion fruit juice using lactose-maltodextrin blends as the support material. Braz. Arch. Boil. Technol. 2009, 52, 1011-1018. [CrossRef]

46. Hogekamp, S.; Schubert, H. Rehydration of food powders. Food Sci. Technol. Int. 2003, 9, 223-235. [CrossRef]

47. Schubert, H. Instantization of powdered food products. Int. Chem. Eng. 1993, 33, $28-45$.

48. Legako, J.; Dunford, N.T. Effect of spray nozzle design on fish oil-whey protein microcapsule properties. J. Food Sci. 2010, 75, E394-E400. [CrossRef] [PubMed]

49. Shishir, M.R.I.; Chen, W. Trends of spray drying: A critical review on drying of fruit and vegetable juices. Trends Food Sci. Technol. 2017, 65, 49-67. [CrossRef]

50. Cai, Y.Z.; Corke, H. Production and properties of spray-dried amaranthus betacyanin pigments. J. Food Sci. 2000, 65, 1248-1252. [CrossRef]

51. Tze, N.L.; Han, C.P.; Yusof, Y.A.; Ling, C.N.; Talib, R.A.; Taip, F.S.; Aziz, M.G. Physicochemical and nutritional properties of spray-dried pitaya fruit powder as natural colorant. Food Sci. Biotechnol. 2012, 21, 675-682. [CrossRef]

52. Yousefi, S.; Emam-Djomeh, Z.; Mousavi, S.M. Effect of carrier type and spray drying on the physicochemical properties of powdered and reconstituted pomegranate juice (Punica Granatum L.). J. Food Sci. Technol. 2011, 48, 677-684. [CrossRef] [PubMed]

53. Peleg, M. Physical characteristics of food powders. In Physical Properties of Foods; Peleg, M., Bagley, E., Eds.; AVI: New York, NY, USA, 1983; pp. 293-323.

54. Bennick, A. Interaction of plant polyphenols with salivary proteins. Crit. Rev. Oral. Biol. Med. 2002, 13, 184-196. [CrossRef] [PubMed]

55. Arts, I.C.; Hollman, P.C. Polyphenols and disease risk in epidemiologic studies. Am. J. Clin. Nutr. 2005, 81, 317S-325S. [CrossRef] [PubMed]

56. Manach, C.; Williamson, G.; Morand, C.; Scalbert, A.; Rémésy, C. Bioavailability and bioefficacy of polyphenols in humans. I. Review of 97 bioavailability studies. Am. J. Clin. Nutr. 2005, 81, 230S-242S. [CrossRef]

57. Surh, Y.J. Cancer chemoprevention with dietary phytochemicals. Nat. Rev. Cancer 2003, 3, 768. [CrossRef] [PubMed]

58. Couto, R.O.; Conceição, E.C.; Chaul, L.T.; Oliveira, E.M.; Martins, F.S.; Bara, M.T.F.; Rezende, K.R.; Alves, S.F.; Paula, J.R. Spray-dried rosemary extracts: Physicochemical and antioxidant properties. Food Chem. 2012, 131, 99-105. [CrossRef]

59. Pavlić, B.; Teslić, N.; Vidaković, A.; Vidović, S.; Velićanski, A.; Versari, A.; Radosavljević, R.; Zeković, Z. Sage processing from by-product to high quality powder: I. Bioactive potential. Ind. Crops Prod. 2017, 107, 81-89. [CrossRef]

60. Donovan, J.L.; Bell, J.R.; Kasim-Karakas, S.; German, J.B.; Walzem, R.L.; Hansen, R.J.; Waterhouse, A.L. Catechin is present as metabolites in human plasma after consumption of red wine. J. Nutr. 1999, 129, 1662-1668. [CrossRef] [PubMed]

61. Kosaraju, S.L.; Labbett, D.; Emin, M.; Konczak, I.; Lundin, L. Delivering polyphenols for healthy ageing. Nutr. Diet. 2008, 65, S48-S52. [CrossRef]

(C) 2019 by the authors. Licensee MDPI, Basel, Switzerland. This article is an open access article distributed under the terms and conditions of the Creative Commons Attribution (CC BY) license (http://creativecommons.org/licenses/by/4.0/). 